\title{
Study of serum cholinesterase, CPK and LDH as prognostic biomarkers in Organophosphorus Poisoning
}

\author{
Sen $\mathbf{R}^{1}$, Nayak $\mathbf{J}^{2}$, Khadanga $S^{3 *}$ \\ ${ }^{1}$ Dr Rajdip Sen, Post graduate student, Department of Medicine, SCB Medical College, Cuttack, Odisha, India. ${ }^{2}$ Dr Jadumani \\ Nayak, Associate Professor, Department of Medicine, SCB medical college, Cuttack, Odisha, India. ${ }^{3 *}$ Dr Sagar Khadanga, \\ Associate Professor, Department of Medicine, LN Medical College, Bhopal, Madhya Pradesh, India.
}

Address of corresponding author: Dr Sagar Khadanga, E mail: sagarkhadanga@yahoo.com

\begin{abstract}
Introduction: Organophosphorus insecticides are arguably one of the commonest causes of morbidity and mortality due to poisoning worldwide, especially in developing countries like India due to its easy availability. This study was conducted to estimate the levels of Serum Cholinesterase, Serum Creatinine Phosphokinase \& Serum Lactate Dehydrogenase on admission for correlation with severity of organophosphate poisoning and to reevaluate their levels on Day 4 and Day 8 and correlate them with the complications and final outcome of the poisoning. Material and methods: This is a single centered cross sectional study over a period of one year.100 patients of OP poisoning were selected and their clinical severity was categorized according to Peradeniya organophosphorus poisoning (POP) scale. Level of serum Cholinesterase, serum CPK, and serum LDH were measured at admission and on Days 4 and 8. Results: Serum Cholinesterase and CPK levels strongly correlated with clinical severity. The comparative values of serum Cholinesterase and serum LDH amongst survivors and non survivors during the course of the study was not statistically significant. The comparative values of serum Creatinine Phosphokinase between survivors and non survivors showed a statistically significant difference. Conclusion: Serum Cholinesterase serves as a diagnostic parameter for organophosphorus poisoning and correlates with the severity but it cannot be used as a prognostic biomarker. Serum Creatinine Phosphokinase shows a strong degree of positive correlation with the severity of poisoning and can be used as a predictor of outcome in organophosphorus poisoning.
\end{abstract}

Key words: Cholinesterase, Creatinine Phosphokinase (CPK), Lactate dehydrogenase (LDH), Organophosphorus (OP), Peradeniya organophosphorus poisoning (POP) scale.

\section{Introduction}

The World Health Organization (WHO) estimates that globally three million intentional or unintentional pesticide poisoning episodes occur annually and out of these a minimum of 300,000 die [1]. It seems these data represent only the tip of ice berg as most cases are not reported from developing nations.

Organophosphorus insecticides are arguably one of the commonest causes of morbidity and mortality due to poisoning worldwide, especially in developing countries like India due to its easy availability. The morbidity and mortality outcome depends on the time lag between exposure and the onset of management. So, it is cardinal to recognize the entire spectrum of the symptoms. Organophosphorus (OP) compounds inhibit acetyl cholinesterase and butyryl cholinesterase enzymes resulting in over stimulation at

Manuscript received: $\mathbf{0 3}^{\text {rd }}$ Apr 2014

Reviewed: $05^{\text {th }}$ Apr2014

Author Corrected: $13^{\text {th }}$ Apr 2014

Accepted for Publication: $10^{\text {th }}$ May 2014

International Journal of Medical Research and Review cholinergic synapses [2]. Symptoms are classified into muscarinic, nicotinic and central depending on the actions over the respective receptors. Muscarinic features include excessive salivation, lacrimation, urination, diarrhea, gastrointestinal cramps, emesis, blurred vision, miosis, bradycardia, and wheezing. Nicotinic features include fasciculation, paresis or paralysis, hypertension and tachycardia. Three types of neuro muscular paralysis are noticed. Type I is due to continued depolarization at neuro-muscular junction, type II due to intermediate syndrome and type III due to delayed polyneuropathy. Central features include anxiety, confusion, seizures, psychosis and ataxia [3, 4].

The quest for newer biomarkers in relation to $\mathrm{OP}$ compound poisoning started quite a long time back. OP labeled albumin in plasma, blood $\beta$-glucuronidase and paraxonase status have been suggested by some researchers to be very reliable marker for both diagnosis and prognosis. But all these assays are dependent on Available online at: $\underline{\text { www.ijmrr.in }} \mathbf{1 8 5}$ | P a g e 
specialized laboratories and costly. Many studies have been undertaken to investigate the diagnostic and prognostic value of serum cholinesterase levels in organophosphorus (OP) poisoning and their relationship with the neurological syndromes (intermediate syndrome and delayed polyneuropathy) $[5,6]$.

Most of the studies have shown that though serum cholinesterase can be used as a diagnostic marker, its role is minimal as a prognostic marker [7,8]. So cheap and easily measurable biomarkers having prognostic value is the need of the hour [9-12].

It was proved beyond doubt that rhabdomyonecrosis occur in animals after experimental poisoning by OP compounds [13]. After the publication of this study in 1993, there have been many human studies which show elevations in Serum CPK and Serum LDH levels following acute OP poisoning as a result of muscle injury. There is also biopsy proven evidence of muscle fiber necrosis in humans [14].

A number of recent studies have been carried out using parameters like serum $\mathrm{CPK}$, serum $\mathrm{LDH}$, serum amylase, liver enzymes and urine creatinine levels as new markers and their correlation with the severity and prognosis of OP poisoning [9- 12]. This study is conducted to observe if the levels of Serum Cholinesterase, Serum CPK and Serum LDH can be used to assess the severity of OP poisoning and to serve as prognostic biomarkers of $\mathrm{OP}$ poisoning

\section{Material \& methods}

This is a cross sectional study which was conducted in a tertiary health care centre over a period of one year. Detailed examination was conducted with a preset questioner.

\section{Inclusion criteria}

1. Age more than 15 years and

2. Who has consumed OP compounds and

3. Who have arrived to the hospital within $6 \mathrm{hr}$. of consumption.

\section{Results}

Out of the total 100 cases, females outnumbered the males (57 Vs 43). Looking at the demography, majority of patients were from low socioeconomic strata and were young. Forty out of 100 patients were in the age group between 15 and 24 years of age. Fixed dose preparation of Chlorpyriphos and Cypermethrin was the most common type of compound used for poisoning (28 out of 100 cases) followed by Phorate (23 cases) and Chlorpyriphos (15 cases). Other OP compounds encountered were Acephate, Malathion, Parathion, Propenophos, Quinalophos, and Triazophos. Salivation and vomiting were the most common symptoms (in 77 and 75 cases respectivlly) followed by abdominal pain/loose motion in 24 cases. Bradycardia was the most common symptom followed by constricted pupil and tachypnoea (in 69, 64 and 56 cases respectively).

\footnotetext{
International Journal of Medical Research and Review Available online at: www.ijmrr.in 186 | P a g e
} 
Table 1: POP scale and correlation with mean serum cholinesterase, CPK and LDH at the time of admission

\begin{tabular}{|l|l|l|l|l|}
\hline POP score & $\begin{array}{l}\text { No. of } \\
\text { patients }\end{array}$ & $\begin{array}{l}\text { Serum cholinesterase } \\
\text { Mean } \pm \text { SD }\end{array}$ & $\begin{array}{l}\text { Serum CPK } \\
\text { Mean } \pm \text { SD }\end{array}$ & $\begin{array}{l}\text { Serum LDH } \\
\text { Mean } \pm \text { SD }\end{array}$ \\
\hline $0-3$ & 29 & $2006.75 \pm 1554.7$ & $449.65 \pm 325.4$ & $329.0 \pm 125.47$ \\
\hline $4-7$ & 45 & $1389.27 \pm 1544.0$ & $768.2 \pm 485.4$ & $480.31 \pm 310.05$ \\
\hline $8-11$ & 26 & $838.70 \pm 699.59$ & $1324.74 \pm 141.6$ & $497.88 \pm 321.87$ \\
\hline
\end{tabular}

According to the severity of poisoning as per the POP Scale, 29 patients ( 23 female and 6 male) had mild poisoning, 45 had moderate poisoning (22 females and 23 males) and 26 (12 females and 14 males) had severe poisoning. Patients having mild, moderate and severe poisoning were grouped and it was seen that with increase in the severity of poisoning, there is a decrease in the mean value of S. Cholinesterase level and increase in the mean value of S. CPK and S.LDH (Table 1).

There was negative correlation (Pearson coefficient $r=-0.267$ ) between severity of poisoning and serum Cholinesterase levels and the correlation was statistically significant $(p=0.001)$. The correlation between severity of poisoning and serum CPK showed a high degree of positive correlation $(\mathrm{r}=0.625)$ and the correlation was also statistically significant $(\mathrm{p}=$ 0.001). The correlation between serum LDH and severity of poisoning was also positive with a value of $r=0.291$, but not statistically significant.

Among the de novo in hospital complications respiratory acidosis was most common and was found in $55 \%$ cases. 15 patients ( 9 male and 6 female) developed the dreaded intermediate syndrome. Other documented complications were seizure (7 male and 3 female) and coma ( 4 male and 2 female). The hospital mortality rate was $22 \%$. None of the patients died from the mild poisoning group. Five patients ( 3 male and 2 female) having moderate poisoning and 17 patients (10 male and 7 female) with severe poisoning succumbed during the treatment.

Table 2: Comparison of mean serum cholinesterase values in survivors and non survivors on day 1, 4 and 8

\begin{tabular}{|l|l|l|l|l|}
\hline Day & $\begin{array}{l}\text { Survivors cholinesterase Mean } \\
\pm \text { SD }\end{array}$ & $\begin{array}{l}\text { Non survivors cholinesterase } \\
\text { Mean } \pm \text { SD }\end{array}$ & Difference & P value \\
\hline Day 1 & $1593.23 \pm 1539.2$ & $802.80 \pm 652.97$ & 790.43 & 0.0225 \\
\hline Day 4 & $1935.33 \pm 1497.8$ & $1189.03 \pm 1023.06$ & 746.33 & 0.0707 \\
\hline Day 8 & $2264.74 \pm 1413.8$ & $1745.00 \pm 1662.6$ & 519.74 & 0.9870 \\
\hline
\end{tabular}

There was statistically significant rise in the initial and final mean values of serum Cholinesterase in cases of mild poisoning but the difference was not statistically significant in moderate or severe poisoning. Serum Cholinesterase values show a progressively increasing value in both survivors and non survivors (Table-2).

Table 3: Comparison of mean serum CPK values in survivors and non survivors on day 1, 4 and 8

\begin{tabular}{|l|l|l|l|l|}
\hline Day & $\begin{array}{l}\text { Survivors CPK Mean } \\
\pm \text { SD }\end{array}$ & $\begin{array}{l}\text { Non survivors CPK } \\
\text { Mean }( \pm \text { SD) }\end{array}$ & Difference & P value \\
\hline Day 1 & $698.58 \pm 486.48)$ & $1277.81 \pm 645.23)$ & 579.23 & 0.002 \\
\hline Day 4 & $595.37 \pm 587.32)$ & $1180.54 \pm 729.94)$ & 585.17 & 0.0017 \\
\hline Day 8 & $332.527 \pm 276.97)$ & $986.5 \pm 635.34)$ & 654.0 & 0.710 \\
\hline
\end{tabular}

However, the serum CPK levels showed a statistically significant difference between the initial and final values in mild, moderate and severe poisoning. In comparative studies between survivors and non survivors, the difference between mean $\mathrm{S}$. CPK levels in survivors and non survivors on Days 1 and 4 were statistically significant in mild and moderately severe cases ( $p$ values of 0.002 and 0.0017 respectively). In survivors, the levels of serum CPK showed a progressively decreasing trend while in non survivors; the CPK value remained persistently elevated above 900. The study also showed that if the Serum CPK value remains persistently above $900 \mathrm{IU} / \mathrm{L}$ throughout the course of the disease, it is associated with the development of complications and with higher mortality rate (Table-3). 
Research Article

The serum LDH levels did not show statistically significant difference between the initial and final values in mild, moderate or severe poisoning. In comparative studies between survivors and non survivors, the difference between mean serum LDH levels in survivors showed a progressively decreasing trend but the difference in values between survivors and non survivors was not statistically significant.

\section{Discussion}

Looking at the demographic profile in our study it is no wonder that most of the patients are from low socioeconomic status and young. This young age presentation is probably due to the fact that that they are more emotionally liable and jobless which make them more vulnerable to contemplate drastic steps like suicide. Female has outnumbered males in our study emphasizing the fact of more labile emotions in them. But looking closely it is evident that maximum cases among females are mild to moderate ( 45 out of 57 cases) where as in males maximum cases were moderate to severe (34 out of 43 cases). This is very unfortunate to know that so many young people are dying consuming this easily accessible notorious insecticide. So there must be some constraints for its availability in the market.

Yves Vanneste \& Dominique Lisson had shown that rhabdomyonecrosis occurs after organophosphate poisoning and was accompanied by a concurrent increase in serum total creatine phosphokinase activity and urinary creatine excretion rate [13]. In a study performed by M. John, A. Oommen, A. Zachariah in Christian Medical College Vellore, muscle injury was seen in all patients beginning at admission, peaking over the first 5 days and then declining over the next 5 days. Temporal profiles of muscle isoenzyme of CPK showed significantly greater muscle injury in those patients with greater severity of poisoning at admission, those who developed intermediate syndrome and in patients with longer duration intermediate syndrome. The mechanism of acetylcholinesterase inhibitor-induced myopathy has been described as an "agonist-induced myopathy" with per-junctional sarcoplasmic swelling and organelle damage, Z band destruction and focal contractures. In our study also we observed that serum CPK level is elevated even in the absence of intermediate syndrome, provided the patient is severely poisoned, presumably due to muscle fiber necrosis. There is a strong positive correlation between the clinical severity of poisoning and the initial levels of serum CPK. If there is ongoing injury to the muscle due to development of complications, the CPK level continues to be elevated. In other words high and persistent serum CPK can be taken as a marker of impending complications.

In our study, there was negative correlation (Pearson coefficient $r=-0.267$ ) between severity of poisoning and serum Cholinesterase levels and the correlation was statistically significant $(\mathrm{p}=0.001)$. This means that serum Cholinesterase levels can be a reliable biomarker for the diagnosis. But the comparative values of serum Cholinesterase amongst survivors and non survivors during the course of the study were not statistically significant suggesting that it is not a reliable indicator for prognosis. So it can only be used in diagnosing suspected OP compound poisoning at present without any prognostic significance.

The comparative values of serum CPK between survivors and non survivors during the course of the study showed a statistically significant difference suggesting that it can be used as a measure of prognostic significance. To be more specific if the Serum CPK value remains persistently above $1000 \mathrm{IU} / \mathrm{L}$ throughout the course of the disease, it is associated with higher rate of complications and mortality. The difference between mean serum LDH levels in survivors and non survivors was statistically not significant suggesting that that it is not a reliable indicator for prognosis and since LDH is not specific to muscle so its elevation does not necessarily point a diagnosis.

\section{Conclusion}

It may be concluded from the study that serum Cholinesterase serves as a diagnostic parameter for organophosphorus poisoning and correlates with the severity but it cannot be used as a prognostic biomarker.

Serum Creatinine Phosphokinase shows a strong degree of positive correlation with the severity of poisoning and can be used as a predictor of outcome in organophosphorus poisoning. Serum Lactate Dehydrogenase can neither be used as a marker of severity nor as a prognostic biomarker. The study has its own limitations as it was carried out involving a relatively small number of subjects with limited parameters. Further studies involving different parameters with a larger number of patients may be carried out to validate the accuracy of our study claiming that serum CPK can be used for the predictor outcome in OP poisoning.
Funding: Nil
Conflict of interest: Nil

Permission from IRB: Yes

Available online at: $\underline{\text { www.ijmrr.in }} 188$ | P a g e 


\section{References}

1. Mancini, Francesca, Janice LS Jiggins, and Michael O'Malley. "Reducing the incidence of acute pesticide poisoning by educating farmers on integrated pest management in South India." International journal of occupational and environmentalhealth15.2(2009):143-151

2. Cander,Ali Dur,Mesut Yidiz. The prognostic value of Glasgow Coma Scale, serum acetyl cholinesterase \& leucocyte levels in acute Op poisoning. Basar Annals of Saudi Medicine 2011 Mar-Apr 31(2) 163-166.

3. David A Warrel, Timmothy M Cox, John D Firth. Oxford Text Book of Medicine $5^{\text {th }}$ edition edition. 2003 ;vol 1:906-907p.

4. Edward T Bake,Rick Kellerman. Conn's Current Therapy 2013: 1175-76p.

5. Akdur O,Durukan P,Ozkan S. Poisoning severity scale,Glasgo Coma Scale,corrected QT interval in acute OP poisoning; Department of Emergency Medicine ,Canakkale, Turkey; Human experimental toxicology 2010,May29(5)419-25.

6. HW Yun,DH Lee,JH Lee,YJ Cheon. Serial serum cholinesterase activities as a prognostic factor in onganophosphate poisoned patients; Hong kong journal of Emergency Medicine-Vol.19(2),Mar.2012.

7. T S Aravanapavananthan. Serum Pseudocholinesterase estimation in the management of organophosphate poisoning cases and the effect of PAM on regenerating it. Singapore Med J. 1987; Vol. 28, No. 2: 166 - 171.

8. Aygun D, Doganay Z, Altintop L, Guven H, Onar M, Deniz $\mathrm{T}$ et. Serum acetylcholinesterase and prognosis of acute organophosphate poisoning. J Toxicol Clin Toxicol 2002; 40: 903-910. 3.
9. S Agarwal, V Bhatnagar, A Agarwal, U Agarwal, K Venkaiah, S Nigam, S Kashyap. Impairment in Clinical Indices in Acute Organophosphate Insecticide Poisoning Patients in India. The Internet J of Toxicology. 2006 Volume 4 Number 1.

10. Kuntal Bhattacharyya, Sibaji Phaujdar, Rathindranath Sarkar, Omar S. Mullick. Serum Creatinine phosphokinase:A probable marker of severity in Organophosphorus poisoning Toxicol Int. 2011 JulDec; 18(2): 117-123.

11. Lee WC, Yang CC, Deng JF, Wu ML, Ger J, Lin HC, Chang FY, Lee SD. The clinical significance of hyperamylasaemia in organophosphate poisoning.J Toxicol Clin Toxicol. 1998;36(7):673-81.

12. I Sahin,K Onbasi. The prevalence of pancreatitis in organophosphate poisonig; Department of Internal Medicine ,University of Yuzuncu,Turke; Human experimental toxicology 2000 Apr.21(4)175-177.

13. Vanneste, Yves, and Dominique Lison. "Biochemical changes associated with muscle fibre necrosis after experimental organophosphate poisoning." Human \& experimental toxicology 12.5 (1993): 365-370.

14. John, M., A. Oommen, and A. Zachariah. "Muscle injury in organophosphorous poisoning and its role in the development of intermediate syndrome."Neurotoxicology 24.1 (2003): 43-53.

15. Senanayake, Nimal, H. J. De Silva, and Lakshman Karalliedde. "A scale to assess severity in organophosphorus intoxication: POP scale." Human \& experimental toxicology 12.4 (1993): 297-299.

\section{How to cite this article?}

Sen R, Nayak J, Khadanga S. Study of serum cholinesterase, CPK and LDH as prognostic biomarkers in Organophosphorus Poisoning. Int J Med Res Rev 2014;2(3):185-189.doi:10.17511/ijmrr.2014.i03.03 